\title{
Interaction Technologies Used in Intelligent Residences: A Systematic Review
}

\author{
Renata R. de Oliveira, Kamila Rios da H. Rodrigues, Vânia Paula de A. Neris \\ Department of Computer Science. Federal University of São Carlos, São Carlos, SP - Brasil \\ renata.oliveira@ufscar.br, kamila.rios@gmail, vania@dc.ufscar.br
}

\begin{abstract}
Sustainability is an updated research topic. In Computer Science, researchers especially from Human-Computer Interaction and Software Engineering areas have started to focus on how to design and build more sustainable technologies and mainly how to build technologies that could help us to live in a more sustainable way. In this last sense, several solutions have been studied and developed to be used at home. The concept of sustainable houses is growing and generally relies on technological solutions which we should interact with. However, how human-centered aspects have been considered in these works? Which aspects of sustainability have been addressed? In this work, we present a critical view on the works found in literature and also a discussion about the research gap considering the design and evaluation methodologies for such technology.
\end{abstract}

\section{Introduction}

Sustainability issues are gathering strength on the world stage, and attracting attention from both central governments and local authorities, as well as the general public. Being sustainable goes far beyond questions, such as recycling waste or water conservation, and should be a habit that is ingrained in all our everyday activities; this not only applies to the environment, but also to economic issues and the people around us [Neris et al. 2016]. Concern for sustainability should not only include large companies but also our homes, where we spend much of our time. There are a significant number of residential dwellings, and it is essential to include these in studies on sustainability. In view of this, the aim of this systematic review is to understand and conduct a critical analysis of: i) what computer technologies are being developed that can provide the most sustainable form of home environment, ii) how these are being created/designed, iii) how people are interacting with them and iv) and what impact they are having on sustainability.

Since sustainability has been viewed from different perspectives, it is necessary to provide a definition of this concept. According to the Brundtland Report (1987) sustainable development is all that "meets present needs without compromising the ability of future generations to meet their own needs." On this basis, it is necessary to take care of both the environment and social and economic issues, so that we can achieve a future, that ensures the perpetuation of the species and our heritage.

Environmental issues include environmental conservation and measures for the reduction of greenhouse gas emissions and the use of fossil fuels. The economic questions involve income distribution, and measures that are economically viable. Finally, social issues should encourage a respect for differences between people and be concerned with human rights [Neris et al. 2016], [Neris et al. 2014]. When addressing questions of sustainability, it is essential to bear these three factors in mind. 
Computers play a key role in disseminating knowledge and changing habits with a view to promoting sustainability, since, in most countries the vast majority of the population has access to computing devices. In the light of this, the challenge for the HCI community [Nathan et al. 2009], [Neris et al. 2016] is how to encourage more sustainable kinds of interaction, that can lead to intelligent ways of behaving, living and coexisting in society, in the interests of collective well-being. Building and making use of sustainable computing solutions, means being fully aware of environmental, social and economic factors [Blevis 2007].

Sustainability in computing began gradually and was largely concerned with recycling material and today there are already several studies on sustainability in the areas of Software Engineering [Nathan 2008] and Human-Computer Interaction [Chen et al. 2013], [Neris et al. 2016], that seek to investigate how technological factors can influence human life, habits and people's values.

Houses can be designed to be sustainable, by taking account of physical factors and knowledge derived from Civil Engineering. Moreover, there is a growing interest in the concept of sustainable houses which generally rely on interactive technology solutions. This raises the question of how human-centered factors have been regarded in these works. What aspects of sustainability have been addressed? With the aim of obtaining a comprehensive view of the academic research on interactive technologies for sustainable houses, we decided to carry out a systematic review in four scientific computer science databases. As a result, we are able to provide a critical overview of some of the works found in the literature and also conduct a discussion about gaps in research with regard to the design and evaluation methodology required for this technology.

\section{Related Works}

The theme "Sustainable HCI" had the its first appearance at CHI (Conference on Human Factors in Computing Systems) conference in 2007 and since then, it became the nascent subfield and it has exploded, according to DiSalvo and Brynjarsdóttir (2010).

In 2009, Goodman (2009) identified 120 papers related to the topic of the environment in HCI. DiSalvo and Brynjarsdóttir (2010), in turn, found 157 papers related to sustainability. These last authors pointed that they were struck by the remarkable heterogeneity of methods, orientations, and approaches, which have contributed to the rubric of sustainable HCI. They provided a reflective lens for practitioners of sustainable HCI, seeking to allow for principled, reflective discussion of how the community has, until 2010, defined sustainable HCI, and how this community might best choose to do so in going forward.

Froehlich, Findlater and Landay (2010), describe the named "Eco-feedback" technology, which "provides feedback on individual or group behaviors with a goal of reducing environmental impact". The authors pointed that the history of eco-feedback has the origins of environmental psychology, but, few HCI eco-feedback studies have attempted to measure behavior change. They lead to two overarching questions, that include to understand what can HCI learn from environmental psychology and what role HCI have in designing and evaluating eco-feedback technology. The authors identified 89 papers from environmental psychology and 44 papers from the HCI and UbiComp literature. They provided an overview of predominant models of pro-environmental behaviors and a summary of key motivation techniques to promote this behavior.

Pierce and Paulos (2012), presented a review of energy-related work within HCI as well as from literature outside of HCI. The authors' review of energy-related HCI research identified a central cluster of work focused on Electricity Consumption Feedback (ECF). 
They outlined a range of opportunities for "HCI to engage with the experiential, behavioral, social, and cultural aspects of these emerging systems, including highlighting new areas for ECF research that move beyond our field's current focus on energy feedback displays to increase awareness and motivate individual conservation behavior".

\section{Methodology}

In order to obtain a comprehensive view of the academic research on interactive technologies for sustainable houses, as well as to understand how human-centered factors have been regarded in these works, and what aspects of sustainability have been addressed, we carried out a systematic review literature (SLR) based in Kitchenham. (2007) in scientific computer science databases. This is an exploratory method and four bases for selecting articles were chosen, which were based on their relevance to the area of computing. These are: 1) ACM Digital Library; 2) IEEE Xplore Digital Library; 3) SCOPUS; 4) Engineering Village - Compendex.

\subsection{Recovered Works and Guiding Questions}

In all, 318 papers were returned with the two search strings, 68 of which remained for reading, after the application of the criteria for inclusion and exclusion. However, some papers were found in more than one database and thus, 29 papers were left for reading to avoid duplication of the papers.

The analysis of the selected articles was based on a set of guiding questions in order to find some answers. The questions were: Q1 - What technologies are being developed to leave the most sustainable home environment? Q2 - What theoretical framework has been adopted? Q3 - What methods for the evaluation of interaction between the user and technology have been adopted? Q4 - What kind of interaction (e.g. voice, tactile) have been employed? Q5 - What is the expected impact of sustainability?

\subsection{Search String}

Two search strings were used for the return of the sought items, in an attempt to that no important bibliographical material was left out of our research, and for this reason, we chose a complementary string. First searches were carried out by the string: ("sustainable house" or "sustainable home" or "sustainable residence") and ("application" or "solution" or "framework")) between the years 2011-2016, and a search supplement was made with the following search string: (("sustainability" or "sustainable") and ("home" or "house" or "residence") and ("human-computer interaction" or "computer-human interaction" or "HCl" or "CHI" or "user")). These strings were selected by the proximity of the theme and by grouping the topics of interest of this research.

\subsection{Inclusion and Exclusion Criteria}

The returned items in the databases by means of the strings were selected on the basis of inclusion and exclusion criteria, with the aim of making an analytical adjustment to the interaction factors. The criteria for the inclusion of items in the survey were as follows: a) Papers that address the question of sustainability for the home, and employ some kind of computer support for this purpose, hardware and/or software; b) Items that involve user interaction with computer tools which are aimed at the sustainability of the home. All of works that complied with these criteria were included in the survey.

The criteria for exclusion of the papers found were as follows: a) Papers that not address the issue of sustainability during the period when the houses were being built; $b$ ) 
Works that do not address the issue of user interaction or computing solutions for sustainability; c) Papers that are concerned with locations other than the domestic environment; d) Works that are not classified as scientific papers, such as posters and workshop presentations; e) Works already considered duplicitous

\section{Analysis of the Works}

The study of the interactions between intelligent people and systems has made great strides, but is still in the early stages in terms of application of intelligent systems in domestic sustainability [Alan et al. 2016]. Civil construction advanced on the theme and there are systems aimed at reducing energy consumption, reducing gas emissions that contribute to the greenhouse effect, reduction and reuse of water, introducing device management that can facilitate all these processes, and encouraging an awareness of consumer habits. In general, the aim of these systems is to promote and support sustainability.

People tend to take cost-effective measures and support sustainability when this has a direct influence on their everyday financial expenses [Chetty et al. 2009], [Kjeldskov et al. 2015], [Murugesan et al. 2013]. When the people has access to the statistical information about expenditure on consumption, they have a greater motivation to act in a more sustainable way, because of his financial responsibilities to the family [Sugarman and Lank 2015]. According to Scanetti and Casalegno (2014), it is necessary to think of the sustainability of the house in different ways, and the project needs to consider use of sustainable materials, as well as the use of clean energy such as solar, which does not degrade the environment. Technological resources can help in the design and maintenance of sustainable home.

Kamilaris and Pitsillides (2013) pointed out that the interoperability of the equipment used in smart houses is still a challenge. Manufacturers often use their own ways and protocols, and these are often not feasible for integrated solutions. One way of avoiding this problem is to adopt web systems, with the HTTP protocol for communication, which can allow scalability and integration between devices.

The other papers identified in the review with a focus on sustainability in the domestic environment were classified in the following categories: Eco-feedback, Regionalization of Solutions, Autonomous Systems, The Power of the Families, Changing Habits, The Motivation to Change Habits and Water Saving, as discussed below. These categories emerged after analyzing the main topics covered in the papers found.

\subsection{Eco-feedback}

The mobile technology has been a great ally to changing habits. Several studies have borne witness to this statement and the fact that it can to allow that the user to acquire information [Chetty et al. 2009], [Miller and Buys 2010], [Paay et al. 2013]. Users tend to be more sustainable when they can measure, for example, the amount they spend on energy or water [Combe and Harrison 2014]. If the users are unaware of this kind of information, they lose control of their finances and often spend more than they should or need to. For Chetty et al. (2009), these are consumer habits cultivated over several generations, who had no severe concern with existing resources. Providing feedback to the users and make them more aware on spending, can to give them a responsibility before no existent about the resources [Kjeldskov et al. 2015], [Lombardi et al. 2013].

The facility of access to information and the suggestion of an eco-feedback translate into a change in behavior over time [Lombardi et al. 2013], [Paay at al. 2013]. So, the 
access to these consumer information is as important as the adaptability of them to the new scenario. The systems guided by habit changes through eco-feedback [Yang and Newman 2013] has proved somewhat effective at the start of the studies, but with fall efficiency after some time, given that these systems depend on motivation user in the correct conduction and persistence to maintain the economy. Thus, the eco-interaction proposed by Yang, Newman and Forlizzi (2014) suggests one approach centered on the designer's interface and not centered on the user, in which, according the authors, can reduce the need for people to make a conscious choice. The share of eco-feedback actions is important, and should be designed not only for individual use more also for the collective [Clear et al. 2013], the use of this feedback helps create healthy comparisons between people, which it is mirrored in positive references [Kos and Souza 2014], [Paay et al. 2013].

\subsection{Regionalization of Solutions}

Regional factors should also be taken into account when constructing technologies for sustainable houses [Kamilaris and Pitsillides 2013], [Paay et al. 2013]. Some kinds of technology that are very important in some countries, may not make much sense in others, such as a thermostat that regulates the temperature at one very low. This would not be of much assistance for reducing resource utilization if this same equipment was used in a region where there is a mild climate all year round.

Social sustainability, (one of the pillars that underpins sustainability) is closely linked to quality of life issues, and harmonious and cooperative behavior. It also involves training people to be creative, and respect local culture and diversity. The house provides a link between its inhabitants and the place, so ethnographic issues should be based on what the house can "teach" its occupants, i.e. the principles of sustainability [Scanetti and Casalegno 2014].

\subsection{Autonomous Systems}

Autonomous systems are used so that the user can take advantage of a solution, without having to make a great effort. These systems are usually pre-programmed to suit the preferences of the users, and operate without the user having to do any work. A study carried out by Alan et al. (2016) stated that when the system is autonomous, and the user is unable to exercise control over it, or handle system failures, it is already regarded as useless, and hence abandoned by the user. Currently, there are studies in the literature on these interactions, which for the most part, involve the use of prototypes [Alan et al. 2016], [Kjeldskov et al. 2015], [Chetty et al. 2009]. The area of sensitive context systems might be an alternative to autonomous systems, as a means of providing help in learning the users' preferences [Fréjus et al. 2013], [Moghaddam et al. 2016], by targeting a number of relatively minor flaws and making a comparison with static systems. It is possible, for example, to select the correct temperature thermostat, depending on the number of people that are in a controlled environment, or to suit one's schedule. Moreover, this information about the weather can be combined to regulate the temperature according to user's preference and also to the weather [Moghaddam et al. 2016].

Thermostats that controls ventilation and temperature of residences [Yang and Newman 2013] had been advanced and assumed a predictive control, reasoning that after some time of interaction with equipment, people decreased their interaction with the same, losing the opportunity to save energy [Yang, Newman and Forlizzi 2013].

Few of these studies have been conducted with real people, but the study of Yang and Newman (2013) with the thermostat, brings a considerable sample of the population of the technology area. This sample can have compromised the results, once that these people 
are already accustomed to the technology in their life. But, this study showed that even these people had difficulties with the use of equipment used in the study.

Sugarman and Lank (2015), during interview with users, revealed that after the discovery period the users tend to leave the motivation. The authors consider that the use of design templates and mental user models can assist in construction technologies to foster sustainable behavior, combining this behavior to the comfort and satisfaction of people in your own home. It is necessary that householders are the first captivated by the system, thus delivering the awareness for the whole family. They also argue that the design of these solutions need to be focused on users, so that the rejection of the system is as small as possible.

With a sustainable design, it is possible to provide persuasion and motivation through other ways, beyond the economy. However, many of people does not feel motivated to sustainability actions and nether to preserve resources of the planet [Sugarman and Lank 2015].

Combe and Harrison (2014) evaluated the design of the thermostat for residential energy saving. The authors argue that currently often solutions are focused only on solving the problem, but do not care if the user is able to utilize the solution. This work considered the following issues: text and font size, visual concreteness of the symbols and letters, metrics for measuring time and temperature, dexterity, size of the buttons, interaction style. According authors, from the largest user interaction with the solution, the potential savings with the thermostat increases, because the proper use of it can it become more efficient.

\subsection{The Power of the Families}

Domestic food is also linked to the issue of sustainable houses [Clear et al. 2013]. The conscious choice of food leads to sustainability, since the food production until its preparation. Clear et al. have shown that meat products, for example, are quite damaging to the environment. This occur because of the gases that are emitted (and the greenhouse effect) and also, because the amount of water required for raising the cattle. Added to this, the amount of energy spent on cooking this food, when comparing with the preparation of vegetables.

Awareness about energy saving with regard to food must start with the cooking utensils used for food preparation. More efficient utensils, such as pots that retain heat or cookers that are smaller, have a higher rate of energy efficiency. The utensils should be combined with foods produced with less damage to the environment, and in communities where the production is organic e of subsistence, for example. This is way of contributing to sustainable residential [Clear et al. 2013]. The Fresnel is an example of the compact stove that uses solar energy for cooking [Ali and Yosra 2014]. The prerequisite to make it work is to have sunlight. Thus, it is possible to abandon traditional ways of cooking, that had been considered harmful to the environment, such as the wood stove - that encourages deforestation and emits soot, or a gas stove - that is a contributory factor to global warming. The design of the Fresnel, according Ali and Yosra, is user-centered and was developed after studies, which eliminated some design problems, such as the risk of either burning one's hands or the food while doing the cooking.

\subsection{Changing Habits}

According to Kos and Souza (2014), professional practices have a great deal of influence on the construction and creation of sustainable homes. Professionals can prepare the new technology for users and, demonstrate its use and from this, its popularity can spread. It is often necessary to have a multidisciplinary team on the project to provide that everything in the house works effectively and people can live there, in a harmonious way [Lyle, Choi and Foth 2015]. 
HAISS software, related by Kos and Souza (2014), is an important computational support in the acquisition of sustainable living. It brings a wealth of information aimed at changing user habits, as well as monitoring the consumption of water, energy and greenhouse gases separately, and "educating" users to be more aware of their consumption habits. It is possible that users may have satisfactory consumer habits even without an intelligent monitoring system of domestic consumption, but with a graphic display of events. Changes can be stimulated by graphic design and the consumer economy, and also can to act as a benchmark, once that the graphics can even allow a comparison to be made between neighbors and/or families [Dirienzo et al. 2014], [Sugarman and Lank 2015].

Wilson et al. (2014) used 'personas' to represent users in a controlled setting for measuring the relationship that people have with their energy source. They described a laundry, where must have a need to change daily habits, by using technologies that are integrated with weather forecasts, for example, so that a least amount of resources is used. On sunny days, it is necessary to avoid using electricity for drying, and to use the outdoor climate for this purpose, this involves being aware of the best time for this measure to be taken, as well as increasing the user's commitment to the environment. Action that can be described as "bad" behavior should be corrected and accompanied by an awareness of the need to target the new generations and thus ensure a more environmentally-friendly future [Sun et al. 2015].

The SESAME system [Fensel et al. 2013], on the other hand, had its interface considered intuitive, with good usability and good level of acceptance by the users studied in the experiment. This system has its behavior similar to the Peak Cutter app. The stimulus of new consumption habits from monitoring devices for energy [Ravishankar et al. 2014] can assist the domestic economy. When consumers know exactly what each equipment requires, the action to be taken for energy saving can be timely and effective.

\subsection{The Motivation to Change Habits}

Thinking about what drives users towards energy saving, Paay et al. (2013) proposed a challenge in the Facebook social network, aim to encourage friends to save energy in their homes. The user should propose a challenge on the social network for a friend and the two could to monitor each other's power consumption, and thus encourage energy saving.

In the studies described here, there are some issues with regard to the application, such as, homes where families have different number of people. In this case, probably, there will be a greater spending of energy. One suggestion pointed by Paay et al. (2013) is that the system can sets a starting point so that the problem of having a large number of people in the houses can be overcome. However, this should not discourage people from facing the challenge of economizing on energy until on the choice of electrical appliances.

\subsection{Water Saving}

Another issue that deserves attention is the waste of water in the world. Fresh water on the planet has become an increasingly scarce commodity, and this is a result of the constant growth in consumption. It is necessary to take measures to ensure an adequate supply of water in the future.

In analyzing this issue, Calero et al. (2013) established a benchmark for the evaluation the water consumption per person in one house. This technique was able to find the average consumption per person and compare it with pre-established patterns of consumption in the region. In this study, it was found that some houses possessed the necessary structure to collect rainwater, and reuse the water from the outlet of the washing machine (as well as the 
shower, which has a lower water flow). With the aid of these equipment it was possible to measure water consumption per person and interestingly in the houses where there were more people, water consumption was lower [Calero et al. 2013].

The rate of water consumption per person, is an indication that people can be persuaded to change their habits. The comparison between ideal patterns leads to a more self-aware consumer. This kind of measurement and stimulus can be applied to any country, by changing the calibration of the benchmark adopted in the consumption of water, in accordance with the conditions of the studied region [Miller and Buys 2010].

\section{Results}

The results of this systematic review on technologies that can support in providing greater sustainability in houses, pointed out that there is still much to be done by considering the end users. The results obtained guided the authors of this research in the understanding of this scenario and of the still existing gaps. When designing sustainable technologies, it is necessary to consider the interests of users of these technologies, as well as their motivation for using such technology.

In summary, Figure 1 illustrates several ways of applying more sustainable procedures to houses, they are: i) economizing water, which can occur in the bathroom, kitchen and garden by installing faucets with intelligent sensors [Chetty et al 2009], [Paay et al. 2012], ii) adopting of tanks in the backyard to storage rainwater for washing clothes and the car, iii) making composting so that food scraps can be used as fertilizer, and iv) energy economy in general, which might include the use of energy-efficient lamps [Kamilaris and Pitsillides 2013], [Lombardi et al. 2013], [Miller and Buys 2010]. These procedures e adoptions can make the house more sustainable, so also preserving the comfort that the same requires.

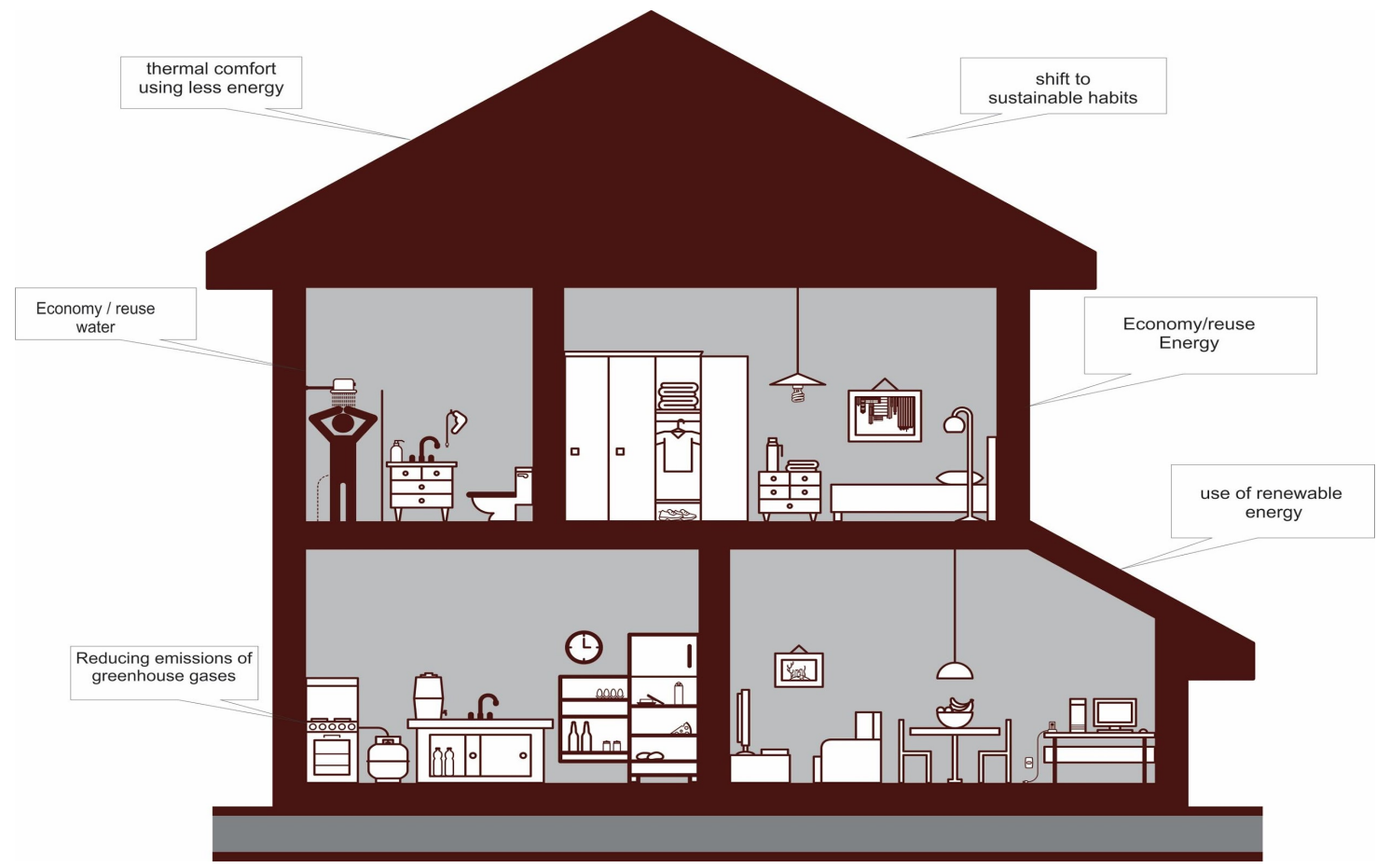

Figure 1. Sketch of a sustainable house. Adapted from: www.pinterest.pt.

Among the equipment pointed, most of them involve the use of thermostats, [Yang et al. 2014], and only one of these studies carried out a concise appraisal of the solution 
with the end users, by identifying factors that induce them not to make use of the solution for house in its entirety, or even, not be able to interact correctly with the solution [Paay et al. 2013]. The most commonly used types of technology for sustainable houses are aimed at changing consumer habits [Chetty et al. 2009], [Dirienzo et al. 2014]. The technologies that influence user consumption, and the subdivisions of this consumption show what equipment is responsible for higher consumption. In many solutions, the system provides information about usage, and statistics, as well as making a comparison with the consumption of other people to stimulate the economy.

By considering the questions defined for this systematic review, to the Q1 question were identified technologies to make the most sustainable home environment around: the recycling/energy saving; reuse/water saving; device management; changing habits; and reducing emissions of greenhouse gases. It was clear that there is a lack of work dealing with reuse and water conservation. This was surprising, given the fact that several places in the world are suffering from a lack of water. The need to reduce greenhouse gas emissions was also rarely mentioned and only three works considered the issue. We believe that this kind of reduction is difficult to put into practice and be measured, although it is essential for the survival of the planet. Most of the measures being studied were concerned with energy saving, changing habits and device management. Only one of the works that discussed the economy/energy reuse, failed to mention the question of changes in the user's behavior. The intelligent management of the devices was also discussed in most of the work related to energy reduction. The reason for this is that, a smart manager can make great improvements to savings by employing user control, and thus prevent oversights and failures from occurring frequently.

Few studies that have cited economic issues such as the use of free software [Ravishankar et al. 2014], which could be framed in low cost solutions and accessible to the entire population, this context is loosely considered. Social issues were fomented in very few jobs as work that is used social network [Paay et al. 2013], [Scanetti and Casalegno 2014], plus the symbiosis between the terms was observed in the survey conducted by creating a gap in the literature.

In response to Q2 questions and what theoretical reference design has been adopted, the reference-points are very diversified and less focused on finding a solution to the problem of a sustainable design. Brynjarsdottir et al. (2012) studied how persuasion narrows our vision of sustainability, and Pierce, Odom and Blevis (2008), studied the interaction design considering Eco-Visualizations. The low references about of sustainable designer are justified because the solutions are very focused to be functional and not userfocused, discarding in this way, this requirement considered essential to the solutions.

About Q3 question and what methods of evaluation of iteration between the user and the technology have been adopted, half the works attempted some kind of evaluation; all of them carried out evaluations by means of interviews with the users [Fréjus et al 2013], [Scanetti and Casalegno 2014]. The interviews were mostly just descriptive, and lacked the application of a methodology to support the design solutions. This is necessary for a more consistent evaluation of the methods employed.

The kind of interaction between the user and the solution for a sustainable house (Q4 question) were mostly tactile, in which touch screens like tablets, smartphones and computers are used to interact with the solution. The visual way is also used in the solutions to provide visual information without the user having access to any modifications that are made [Clear et al. 2013], [Pierce, Odom and Blevis 2008], [Rodgers and Bartram 2010]. Other kinds of interaction could have been included a beep when the limits of consumption passed. There can even be an interaction by voice in a solution that caters for specific 
groups of minorities, such as the blind. The lack of innovative ideas leaves important gaps that need to be filled when designing solutions for sustainable houses.

About the Q5 question and what is the expected impact on sustainability, around $90 \%$ of the selected works only dealt superficially with this issue, and only the remaining $10 \%$ are concerned with assessing the reduction of consumption in general and the changes needed in user behavior to ensure that people can live sustainably [Kjeldskov et al. 2015], [Yang and Newman 2013].

The estimated benefits of the solutions were not considered in the long time, although there are papers on the predicted benefits to the user and the environment. An awareness of the long-time benefits of these solutions could be an added incentive to the users, so long as it converges with their changing habits and they feel motivated to make it happen. However, the fact that the impact of sustainability has not been demonstrated in a clear and consistent way, might be an advantage for those engaged in the task of promoting it.

\section{Conclusion}

The practices involved the development of sustainable homes are still progressing at a slow pace and often only geared to the scenario of the house. Greater attention is needed to areas that have still not been fully explored such as the consumption of water. There is often a lack of a design for the solutions of sustainable home, which shows that there is gap in the literature both in design assessment for solutions aimed at sustainable residence, and innovations for the house.

The modes of interaction between users and these solutions, need to be better exploited so that the solutions are effectively accepted and put into practice. The task of tackling complex issues such as promoting sustainability, is a lost cause if one fails to make use of the solutions available. With the advance of civilization, it is necessary to take effective measures so that future generations can survive to enjoy everything we possess today, and technology is an important ally in this mission.

\section{References}

Alan, A. T., Constanza, E., Sarvapali, R., Joel, F., Tom, R. and Nicholas R. J. (2016). Tariff Agent: Interacting with a Future Smart Energy System at Home. In ACM Transactions on ComputerHuman Interaction (TOCHI) Vol. 23 Issue 4, September 2016, $\mathrm{n}^{\circ} .25$.

Ali, F. and Yosra, D. (2014). Fresnel compact and portable solar cooker design. In Advanced Materials Research. Vol. 933, 2014, 637-642.

Blevis, E. (2007). Sustainable interaction design: invention \& disposal, renewal \& reuse. In: Proceedings of the SIGCHI'07. New York, NY, USA: ACM. 2007.

Brynjarsdottir, H., Hakansson, M., Pierce, J., Baumer, E., DiSalvo, C., and Sengers. P. (2012). Sustainably unpersuaded: how persuasion narrows our vision of sustainability. In Proceedings of the SIGCHI Conference on Human Factors in Computing Systems CHI '12. 947-956.

Calero, C., Bertoa, M. F., and Moraga, M. Á. (2013). A systematic literature review for software sustainability measures. In Proceedings of the 2nd International Workshop on Green and Sustainable Software. GREENS '13. 46-53.

Chen, C., Cook, D. J. and Crandall, A. S. (2013). The user side of sustainability: Modeling behavior and energy usage in the home. In Pervasive and Mobile Computing, vol. 9, n 1, February 2013, 161-175. 
Chetty, M., B, Brian, A. J. B., Meyers, R. and Johns, P. (2009). It's not easy being green: understanding home computer power management. In Proceedings of the SIGCHI Conference on Human Factors in Computing Systems (CHI'09), 1033-1042.

Clear, A. K., Hazas, M., Morley, J., Friday, A. and Bates, O. (2013). Domestic food and sustainable design: a study of university student cooking and its impacts. In Proceedings of the SIGCHI Conference on Human Factors in Computing Systems (CHI'13), 2447-2456.

Combe, N. and Harrison, D. J. (2014). A review and application of usability guidelines relating to domestic heating controls. In Intelligent Buildings International. Vol. 6, Issue 1, January 2014. 26-40.

Dirienzo, T. P., Krishnan, N. A., and Santos, J. R. (2014). Effects of smart appliances on residential consumption patterns. In 2014 IEEE Systems and Information Engineering Design Symposium, (SIEDS 2014), 6829870, 188-192.

DiSalvo, C., Sengers, P., and Brynjarsdóttir, H. (2010). Mapping the landscape of sustainable HCI. In Proceedings of the SIGCHI Conference on Human Factors in Computing Systems (pp. 19751984). New York, NY, USA.

Fensel, A., Tomic, S., Kumar, V., Stefanovic, M., Aleshin, S. V. and Novikov, D. O. (2013). SESAME-S: Semantic smart home system for energy efficiency. In Informatik-Spektrum, v 36, n 1, February 2013, Sonderheft: Energieinformatik, 46-57

Fréjus, M., Dominici, M., Weis, F., Poizat, G., Guibourdenche, J., and Pietropaoli, B. (2013). Changing Interactions to Reduce Energy Consumption: Specification of a Context-Aware System Centered on the Home Occupants' Concerns. In 15th International Conference on HumanComputer Interaction, HCI International 2013.

Froehlich, J., Findlater, L., and Landay, J. (2010). The design of eco-feedback technology. In Proceedings of the SIGCHI Conference on Human Factors in Computing Systems (pp. 19992008). New York, NY, USA: ACM.

Goodman, E. (2009). Three environmental discourses in human-computer interaction. Proc CHI EA '09. ACM, New York, NY, 2535-2544.

Kamilaris, A. and Pitsillides, A. (2013). Towards interoperable and sustainable smart homes. In ISTAfrica Conference and Exhibition (IST-Africa), 2013.

Kitchenham, B. and Charters,S. Guidelines for performing systematic literature reviews in software enginee-ring ering Keele University and and University of Durham, UK, Tech. Rep. Ver. 2.3, EBSE-2007-01, July 2007

Kjeldskov, J., Skov, M. B, Paay, J., Lund, D., Madsen, T. and Nielsen, M. (2015). Facilitating Flexible Electricity Use in the Home with Eco-Feedback and Eco-Forecasting. In Proceedings of the Annual Meeting of the Australian Special Interest Group for Computer Human Interaction (ozCHI'15), 388-396.

Kos, J. R., and Souza, B. M. (2014). Educating home users through a solar house: The Ekó House experience. In Energy and Buildings.vol. 83. 181-185.

Lombardi, M., Francisci, S., Pizzoferro, L. and Stefano, L. C. (2013). Enel Info+ project: A demo to evaluate the impact of the consciousness on the customer energy consumptions. In 22nd International Conference and Exhibition on Electricity Distribution (CIRED 2013).

Lyle, P., Choi, J. H.J., and Foth, M. (2015). Growing food in the city: Design ideations for urban residential gardeners. In ACM International Conference Proceeding Series, v 27-30-June-2015, 89-98.

Miller, W. and Buys, L. (2010). Householder experiences with resource monitoring technology in sustainable homes. In Proceedings of the 22nd Conference of the Computer-Human Interaction Special Interest Group of Australia on Computer-Human Interaction. (OZCHI'10), 228-231.

Moghaddam, R. F., Lemieux, Y. and Cheriet, M. (2016). Federal Smart House Regulator (FSHR): A SelfManaging and Ecosystemic Approach to Resource Management, Automation, and Sustainability in Smart Houses. In 2016 IEEE International Conference on. Cloud Engineering Workshop.

Murugesan, K. K., Hoda, R. and Salcic, Z. (2013). Investigating Visualization of Energy Consumption. In Proceedings of the 14th Annual ACM SIGCHI_NZ conference on ComputerHuman Interaction. (CHINZ'13). 
Nathan, L. P., Friedman, B. and Hendry, D. (2009). SUSTAINABLY OURS: Information system design as catalyst: human action and environmental sustainability. In Magazine interactions The Waste Manifesto. vol.16, Issue 4, July - August 2009. 6-11

Nathan., L. P. (2008). Ecovillages, Values, and Information Technology: Balancing Sustainability with Daily Life in $21^{\text {st }}$ Century America. In Extended Abstracts on Human Factors in Computing Systems (CHI '08) 3723-3728.

Neris, V.P.A., Rodrigues, K.R.H., and Lima, R. (2014). A Systematic Review of Sustainability and Aspects of Human-Computer Interaction. In 16th International Conference on Human-Computer Interaction: Applications and Services, HCI International 2014; Heraklion, Crete; Greece; 22 June 2014. Vol. 8512 LNCS, Issue PART 3, 742-753.

Neris, V.P.A., Rodrigues, K.R.H., and Silva, J. B. (2016). The Future, Smart Cities and Sustainability. In: Baranauskas, Souza and Pereira (org.). I GranDIHC-BR (SBC 2006) Grand Challenges in Computer Science Research in Brazil - 2006 - 2016.

Paay, J., Kjeldskov, J. Skov, M. Pathmanathan, R. and Pearce, J. (2013). Promoting proenvironmental behaviour: A tale of two systems. In Proceedings of the 25th Australian Computer-Human Interaction Conference: Augmentation, Application, Innovation, Collaboration, (OzCHI 2013), 235-244.

Pierce, J., and Paulos, E. (2012). Beyond energy monitors: interaction, energy, and emerging energy systems. In Proceedings of the SIGCHI Conference on Human Factors in Computing Systems (pp. 665-674). New York, NY, USA: ACM.

Pierce, J., Odom, W., and Blevis, E. (2008). Energy aware dwelling: A critical survey of interaction design for eco-visualizations. In 20th Australasian Conference on Computer-Human Interaction: Designing for Habitus and Habitat, (OZCHI'08).1-8.

Ravishankar, A., Vignesh, A., Vel, V., Purusothaman, S.R.R. D. and Vijayaraghavan, V. (2014). Low-cost non-intrusive residential energy monitoring system. In 2014 IEEE Conference on Technologies for Sustainability, SusTech, February 19, 2014, 130-134.

Report of the World Commission on Environment and Development, In General Assembly United Nations. A/RES/42/187. 96th plenary meeting. 11 December 1987.

Rodgers, J. and Bartram, L. (2010). ALIS: an interactive ecosystem for sustainable living. In Proceedings of the 12th ACM international conference adjunct papers on Ubiquitous computing - Adjunct (UbiComp'10), 421-422.

Scanetti, G. and Casalegno, F. (2014). Social sustainability in design: The window as an interface for social interaction. In Cross-Cultural Design. Vol. 8528 of the series Lecture Notes in Computer Science. 321-330.

Sugarman, V. and Lank, E. (2015). Designing Persuasive Technology to Manage Peak Electricity Demand in Ontario Homes. In Proceedings of the 33rd Annual ACM Conference on Human Factors in Computing Systems. (CHI'15),1975-1984.

Sun, X., Wang, O., Wang, N., So, C.S, and Wang, Y. (2015). Design for sustainable behavior. In 17th International Conference on Cross-Cultural Design, CCD 2015 Held as Part of 17th International Conference on Human-Computer Interaction, HCI International 2015, August 2, 2015.

Wilson, G. T., Mackley, K. L., Mitchell, V., Bhamra, T. and Pink, S. (2014). PORTS: An interdisciplinary and systemic approach to studying energy use in the home. In Adjunct Proceedings of the 2014 ACM International Joint Conference on Pervasive and Ubiquitous Computing, (UbiComp 2014), 971-978.

Yang, R. and Newman., M. W. (2013). Learning from a learning thermostat: lessons for intelligent systems for the home. In Proceedings of the 2013 ACM international joint conference on Pervasive and ubiquitous computing (UbiComp'13), 93-102.

Yang, R., Newman, M. W. and Forlizzi, J. (2014). Making sustainability sustainable: challenges in the design of eco-interaction technologies. In Proceedings of the SIGCHI Conference on Human Factors in Computing Systems (CHI'14), 823-832. 